\title{
Crepúsculo, mirabilia e TREVA NO CAMINHO DO POETA VIATOR.
}

CLAUDIO CUCCAGNA

RESUMO: A partir da imagem do poeta viator este ensaio detecta as analogias estruturais, imagéticas e mitopoéticas presentes nos poemas "A ilha de Cipango", de Augusto dos Anjos, e "A máquina do mundo", de Carlos Drummond de Andrade, assim como sinaliza a semelhante e radical atitude dos dois autores em objetivarem uma recusa do mundo pela negaçăo da Utopia.

Palavras-chave: poesia; mito; utopia.

E como a luz do sol vai-se apagando!

E eu triste, triste pela vida afora,

Eterno pegureiro caminhando,

Revolvo as cinzas de passadas eras,

Como um coveiro a sepultar quimeras!

(Augusto dos Anjos, "Soneto") 
Há momentos em que o poeta sente a necessidade de transfigurar toda a sua vida ou uma experiência particularmente sentida dela, na imagem de um caminho, mais ou menos impérvio, que ele se vê percorrendo como um viandante solitário, numa atitude ora exaltada e jubilosa, ora angustiada e tristonha. Clara imagem de reminiscência dantesca, cla tem a força, às vezes, de desenvolver-se numa forma complexa e extensa, como é o caso emblemático, por exemplo, que vemos dar-se em $O$ Guesa de Sousândrade, poema autobiográfico em 13 Cantos, composto durante cerca de 40 anos, onde o poeta-protagonista - o Sousândrade-Guesa-Inca - se aventura numa longa peregrinação pelo suna: o périplo histórico-geográfico da sua missão civilizadora no continente americano e, em parte, africano.

Mas essa imagem do poeta viator, colhido no ato de percorrer um caminho no qual ele evoca a memória do já vivido para, amiúde, relacioná-la simbólica ou alegoricamente com a dimensāo fantástica do mito, pode também se efetivar na intensidade lírica e imagética de um poema com um número mais limitado de estrofes. É o que observamos, de modo claro e similar, em "A ilha de Cipango" (1904), contido no Eu de Augusto dos Anjos, e em "A máquina do mundo", do livro Claro enigma (1948-51) de Carlos Drummond de Andrade. Com efeito, uma leitura comparada dos dois poemas, feita a partir da presença da imagem do poeta viator, mesmo ressaltando os inúmeros traços distintivos peculiares aos dois textos, Jevou-nos à deteç̧ão de umas sugestivas analogias de ordem estrutural, temática e lírica, que os caracterizam, e que nos induzem a considerar o poema augustiano uma espécie de antecedente poético de "A máquina do mundo" drummondiana.

E o confronto começa logo no seu início: o título. Com efeito, se é verdade que o título de uma obra literária constitui parte essencial da mesma, e é portanto ancorado a seu texto no seu modo de vesti-lo, isto é, de apresentá-lo e entregá-lo à inteligência do leitor, então não podemos deixar de frisar uma primeira analogia já na escolha do título que designa os dois poemas em questão. São, de fato, títulos que se refletem de maneira especular tanto do ponto de vista sintático-gramatical quanto do conceitual. E se no primeiro caso a sequiência artigo-substantivo-preposição-substantivo/nome próprio (ou também artigo-nome próprio, se considerarmos, como é lícito pensar, a Itha de Cipango e a Máquina do Mundo dois nomes próprios), cria uma aproximação dos dois títulos um tanto vaga e, por assim dizer, visual, é do lado conceitual que ela se faz mais profunda e patente: ambos os títulos, com efeito, se relacionam com a dimensão e com o espaço do maravilhoso, com a força encantadora do mito, evocando por um lado o locus amoenus da Iha de Cipango, e por outro o objeto fantástico da Máquina do Mundo, e informando, outrossim, da centralidade temática que ambas irão desempenhar no interior dos respectivos poemas. 


\section{O INÍCIO DO CAMINHO: O FIM DO DIA}

O início ex-abrupto de "A Ilha de Cipango" traz consubstancialmente o aparecimento veemente do $e u$ poético, seguido logo depois da fixação do cenário, uma estrada, ao longo da qual começa a peregrinação angustiada do poeta viator Augusto dos Anjos:

"Estou sozinho! A estrada se desdobra

Como uma imensa e rutilante cobra

De epiderme finíssima de areia...

E por essa finíssima epiderme

Eis-me passeando como um grande verme

Que, ao sol, em plena podridão, passeia!"'

1) A. dos ANJOS, Obra completa. Rio de Janeiro: Nova Aguilar, 1996. p. 282.
(2) C. D. de ANDRADE, Obra completa. Rio de Janeiro: Aguilar, 1964. p. 271.

A condição solitária do poeta, devidamente enfatizada pelo uso da apóstrofe, é premissa indispensável à sua peregrinação. No caso, o caráter errático, e, conforme veremos mais adiante, compungido do seu ser, exterioriza-se ao longo de uma estrada que o poeta zoomorfiza na belíssima imagem de uma "cobra / De epiderme finíssima de areia", numa construção simbólica que do plano objetivo (a estrada tortuosa) desliza para o imaginativo (a "imensa e rutilante cobra"), para voltar novamente ao plano objetivo representado pela estrada (pois a epiderme da cobra é de finíssima areia). Tudo isso, segundo uma tendência marcadamente transformista, que, por exemplo, continua na mesma estrofe com a imagem do poeta zoomorfizado $\mathrm{cm}$ verme, o agente do fagismo transformista da poética augustiana.

Em "A máquina do mundo" de Carlos Drummond de Andrade, verificamos a presença de um exórdio análogo, limitadamente no que diz respeito à aparição repentina da subjetividade poética e à imagem do poeta viator passeando por uma estrada, ainda que esta última, uma estrada de montanha, nāo se apresente com as mesmas características morfológicas da representada em "A Ilha de Cipango":

"E como eu palmilhasse vagamente uma estrada de Minas, pedregosa, e no fecho da tarde um sino rouco

se misturasse ao som de meus sapatos que era pausado e seco; e aves pairassem no céu de chumbo, e suas formas pretas

lentamente se fossem diluindo na escuridão maior, vinda dos montes e de meu próprio ser desenganado," 
Como aparece explicitamente registrado no v. 3 com a referência ao "fecho da tarde", sucessivamente complementado por outros indícios cromáticos (o "céu de chumbo"; a "escuridão maior, vinda dos montes"), o poema drummondiano encontra a sua contextualizaçāo temporal no fim do dia, em pleno crepúsculo vespertino. Esta situaçāo temporal, acentuada pelo tom solene e paulatino do andamento diegético do poema, determina o aparecimento de uma identificação simbólica entre o caráter "desenganado" do ser do poeta viator, e o aspecto sombrio da natureza circundante sobre a qual desce o anoitecer.

Em "A Ilha de Cipango" presenciamos uma análoga sequiência de momentos: o do contexto temporal relativo ao fim do dia, e o da aproximação simbólica que se dá entre este e o estado espiritual do poeta, conforme se aprecia na segunda estrofe do poema:

"A agonia do sol vai ter começo!

Caio de joelhos, trêmulo... Ofereço

Preces a Deus de amor e de respeito

E o Ocaso que nas águas se retrata

Nitidamente reproduz, exata,

A saudade interior que há no meu peito..."3

O início desta estrofe, ligado a coblas capfinidas com o último verso da estrofe precedente ("A agonia do sol" / "ao sol") para aumentar o fluxo temporal e o caráter diegético do poema - este último, contudo, menos atuante que o observado em "A máquina do mundo" -, apresenta-nos enfaticamente o momento do fecho do dia, dominado pela imagem do pôr-do-sol. E é com esse "Ocaso" de reminiscência simbolista, e com a imagem que ele reflete nas águas do meio circundante, que Augusto dos Anjos, analogamente a quanto vimos acontecer em "A máquina do mundo" - ainda que num tom cromático bem mais apagado, penumbral e numa projeção simbólica que, no poema drummondiano, a rigor, desloca-se do poeta para o mundo externo -, constrói uma corresponđência simbólica com seu estado de alma, aqui traduzido numa "saudade interior". Pois, em dois poemas ricamente e diversamente imagéticos, o símbolo que surge consubstancialmente com a representaçāo paisagística do fecho do dia, intervém de forma similar para soldar, por meio de uma efusão cromática do estado de alma, uma condiçāo humana de privaçāo e desconsolo a um sentido de precariedade, de transição ínsito na natureza do mundo. $O$ poeta viator passa pelo mundo e interage intimamente com ele.

\section{A PERDA DO SONHO DE FELICIDADE: MIRABILIA PARA O DESENGANO}

Momento crucial dessa minijornada do poeta viator, que se espelha na centralidade quase geométrica dos dois poemas, é a aparição súbita das mirabilia da Ilha de Cipango num, e da Máquina do Mundo noutro; 6 o manejo pessoal 
do mito de que ambos os poetas se valem para poeticamente evocarem uma experiência determinante de sua vida; $\hat{e}$, por fim, a confissão íntima e aflitiva de uma expectativa baldada por causas que se revelam alheias (em Augusto dos Anjos) ou sujeitas (em Carlos Drummond de Andrade) à vontade humana malogro, ademais, que os dois poetas se preocupam em transpor do plano da experiência subjetiva para o de uma condição negativa imanente à existência humana.

Depois do momento temporal e simbólico do pôr-do-sol, seguido por uma descrição angustiada do estado de alma do poeta viator Augusto dos Anjos, que continua se espalhando para o mundo circundante, presenciamos, no início da sexta estrofe, a aparição edênica da llha de Cipango, cuja evocação irá se prolongar até a nona estrofe:

"Mas de repente, num enleio doce,

Qual se num sonho arrebatado fosse,

$\mathrm{Na}$ ilha encantada de Cipango tombo,

Da qual, no meio, em luz perpétua, brilha

A árvore da perpétua maravilha,

À cuja sombra descansou Colombo!

Foi nessa ilha encantada de Cipango,

Verde, afetando a forma de um losango,

Rica, ostentando amplo floral risonho,

Que Toscanelli viu seu sonho extinto

E como sucedeu a Afonso Quinto

Foi sobre essa ilha que extingui meu sonho!

Lembro-me bem. Nesse maldito dia

O gênio singular da Fantasia

Convidou-me a sorrir para um passeio...

Iríamos a um país de eternas pazes

Onde em cada deserto há mil oásis

E em cada rocha um cristalino veio.

Gozei numa hora séculos de afagos,

Banhei-me na água de risonhos lagos

(4) A. dos ANJOS, op. cit,

E finalmente me cobri de flores..."4

p. 283.

O arroubo onírico que desencadeia a aparição é pretexto para que o poeta viator possa momentaneamente suspender a sua peregrinação e entrar de chofre na dimensão da recordação autobiográfica - a infância passada no contexto rural do Engenho Pau d'Arco, onde Augusto dos Anjos nasceu e viveu até 1908, e no qual, em 1904, compôs o poema -, que ele transfigura, num eco 
orientalista caro a certo Simbolismo, na evocação mítica da Ilha de Cipango. $O$ poeta viator re-visita assim seu passado, os lugares naturais intimamente ligados à sua mocidade, através duma caracterização claramente edênica dos mesmos (por exemplo: a árvore de tamarindo do Pau d'Arco, pela qual sabemos que o jovem Augusto dos Anjos nutria grande predileção, toma-se "A árvore da perpétua maravilha"; assim como acreditamos que a referência à "água de risonhos lagos", da última estrofe citada, possa referir-se ao "Lago Encantado", nome com que o poeta designava o açude próximo do Pau d'Arco). Situação edênica, porém, que o poeta perde por causas externas à sua vontade, as quais marcarão temporalmente uma situação conflitante entre um passado cheio de expectativas e um presente de derrota e desalento, como se observa destes versos, continuação dos anteriores:

"Mas veio o vento que a Desgraça espalha

E cobriu-me com o pano da mortalha,

Que estou cosendo para os meus amores!

Desde então para cá fiquei sombrio!

Um penetrante e corrosivo frio

Anestesiou-me a sensibilidade

E a grandes golpes arrancou as raízes

Que prendiam meus dias infelizes

A um sonho antigo de felicidade!"s

O propósito de o poeta enfatizar um momento particularmente esperançoso e também infausto de sua vida, através duma representação que correspondesse à de um status edênico e de sua subseqüente perda, esposava-se brilhantemente quer com a visão paradisíaca, de país da riqueza e da abundância, oferecido pelo nito medieval da Ilha de Cipango - mito geográfico ligado às viagens de descoberta do Novo Mundo -, quer, sobretudo, com a evocação das vicissitudes das personagens históricas de Colombo, Toscanelli e Afonso $\mathrm{V}$, que, convencidos na existência dessa ilha maravilhosa, viram frustrada de todo a esperança de alcançá-la. ${ }^{6}$ Em relação a este último aspecto, o paralelo que Augusto dos Anjos instaura entre a sua dolorosa experiência e a desses homens ilustres do passado, nasce pela necessidade de inseri-la numa continujdade histórica de quimera almejada e nunca lograda; situação, em última instância, que deixa entrever o pessimismo, de cunho schopenahueriano, inerente ao weltanschauung augustiano: o destino do homem é irremediavelmente triste, já que qualquer tentativa de buscar algo de venturoso (o "sonho antigo de felicidade") levará sempre e inevitavelmente ao fracasso (o "sonho extinto"). ${ }^{7}$ É, portanto, à luz deste conjunto de características, que "A Il ha de Cipango" se nos revela qual verdadeiro poema da ilusão e do desengano humanos; assim como, mutatis mutandis, vemos evidenciar-se em "A máquina do mundo" de Carlos Drummond de Andrade.

A aparição do aparelho da Máquina do Mundo, concomitante à sua abertura, acontece no décimo verso do poema ("a máquina do mundo se entrea-
(5) Iidem.

(6) As informações geográficas proporcionadas por Paolo dal Pozzo Toscanelli (1397-1482) sobre a existência da ilha de Cipango ao longe da costa asiática Ásia que ele considerava possível alcançar numa travessia marítima do oceano Atlântico -, foram conhecidas, através da carta e do material cartográfico que este enviou, em 1474, no canônico português Fernando Martins, tanto pelo rei português $D$. 
Afonso V (1432-1481), como por Cristovão Colombo (1451-1506). Este ültimo, graças também aos dados toscanellianos, pôde empreender a sua navegação atlântica em demanda da ilha de Cipango e da terra asiática do Grande Khan. Das duas metas, o objetivo principal da primeira viagem colombiana, que resultou na descoberta do Novo Mundo, foi o da busca dessa ilha misteriosa, que já desde as informaçōes presentes no Milione de Marco Polo e retomadas sucessivamente pelo próprio Toscanelli, aparece com características fantásticas, tida como iltha de incomparável beleza, onde abundavam ouro, pérolas e pedras preciosas. Era tamanho o anseio de achar esta ilha. que em vários momentos do seu Diario de a bordo, Colombo acredita em vê-la nas ilhas caribenhas há pouco descoberas (assim como, paralelamente, pensava de estar próximo do $\mathrm{Pa}$ raíso Terrestre), como resulta dirctamente das suas palavras: "Quisiera hoy partir para la isla de Cuba, que creo que debe ser Cipango, según las señas que dan esta gente [ da Ilha Isabela] de la grandeza de ella y riqueza"; ou através das palavras do padre Las Casas, transcritor $e$ glosador da única versão do Diario de a bordo que possuímos: "entre los otros lugares que nombraban [alguns indígenas da ilha Hispaniola] donde se cogía el oro, dijeron de Cipango, al cual ellos llaman Cibao, y allí afirman que hay gran cantidad de oro de briu"), logo depois do motivo simbólico que une o estado de alma do poeta com o surgimento do anoitecer. Tudo isso sem recorrer ao expediente do onirismo que vimos caracterizar a irrupçāo da Itha de Cipango no poema augustiano. Será, todavia, só no verso 49 que começará a longa descrição do conteúdo deslumbrante da máquina:

\author{
"As mais soberbas pontes e edifícios, \\ o que nas oficinas se elabora, \\ o que pensado foi e logo atinge \\ distância superior ao pensamento, \\ os recursos da terra dominados, \\ e as paixōes e os impulsos e os tormentos
}

e tudo que define o ser terrestre

ou se prolonga até nos animais

e chega às plantas para se embeber

no sono rancoroso dos minérios,

dá volta ao mundo e torna a se engolfar

na estranha ordem geométrica de tudo,

e o absurdo original e seus enigmas,

suas verdades altas mais que todos

monumentos erguidos à verdade;

e a memória dos deuses, e o solene

sentimento de morte, que floresce

no caule da existência mais gloriosa,

tudo se apresentou nesse relance

e me chamou para seu reino augusto, afinal submetido à vista humana."

Esta descrição vorticosa, caleidoscópica do objeto da Máquina do Mundo, que o poeta viator topa sobre uma montanha de Minas Gerais, chama a nossa atenção para outro objeto semelhante que aparece no celebérrimo episódio final de Os Lusíadas de Camōes. Aqui, no verso 640 do Canto $\mathrm{X}$, ele é designado como "a grande máquina do Mundo", e é a deusa Tétis que, na llha dos Amores, em recompensa pelas façanhas marítimas realizadas, mostra esse objeto à tripulação portuguesa para que - a deusa referindo-se a Vasco da Gama - "vejas / Por onde vas [sic] e irás e o que desejas".9 Não é obviamente este o lugar para fazermos um levantamento das diferenças e analogias existentes en- 
tre as duas máquinas e os motivos que as acompanham nos respectivos poemas. Todavia, como interpretações críticas já atestaram, é muito provável que para a transposição mítico-alegórica do tema da busca do conhecimento do sentido da existência, Carlos Drummond de Andrade tenha levado em conta a imagem e o epiśdio da máquina do mundo do poema camoniano. ${ }^{10} \mathrm{Se}$, pois, como é lícito pensar, há uma filiação direta ao mito cantado por Camões, então, à luz disso, podemos vislumbrar duas analogias intercorrentes entre a versão drummondiana do mito da Máquina do Mundo e a versão augustiana do da llha de Cipango: como a Ilha de Cipango, também a imagem da Máquina do Mundo liga-se estritamente à visão maravilhosa da ilha (a Ilha dos Amores); e, dado mais relevante, assim como a primeira, também a segunda se apresenta como um mito relacionado com a tradição literária ibérica das viagens de descoberta/ exploração. Há, pois, no modo de introduzir o tema mítico $\mathrm{em}$ ambos os poemas, um elo subjacente que liga a atitude explícita de Augusto dos Anjos àquela mais implícita de Carlos Drummond de Andrade.

Conforme mencionamos, a Máquina do Mundo constitui para o poeta viator a verdadeira explicação dos mistérios da existência; supremo conhecimento que ele sempre ambicionou possuir através de uma pesquisa apaixonada, embora extenuante e sem resultado, como é o próprio objeto-falante da Máquina do Mundo a referir-nos com palavras dirigidas ao poeta viator, numa situação narrativa que introduz a revelação do segredo da máquina, já vista nos versos anteriores:

\author{
"O que procuraste em ti ou fora de \\ teu ser restrito e nunca se mostrou, \\ mesmo afetando dar-se ou se rendendo, \\ e a cada instante mais se retraindo, \\ olha, repara, ausculta: essa riqueza \\ sobrante a toda pérola, essa ciência \\ sublime e formidável, mas hermética, \\ essa total explicação da vida, \\ esse nexo primeiro e singular, \\ que nem concebes mais, pois tão esquivo
}

se revelou ante a pesquisa ardente

em que te consumiste... vê, contempla,

abre teu peito para agasalhá-lo"."1
A "explicação total da vida", encarnada na imagem e na essência da Máquina do Mundo, aparece aqui como a quimera almejada e nunca lograda que é o "sonho de felicidade" (isto é: o passado vivido por Augusto dos AnjosColombo, no Engenho Pau d'Arco-Ilha de Cipango) do poema augustiano. Além disso, em ambos os poemas é possível reconhecer uma análoga sequiência tem- martillo". As citações são extraídas de $C$. COLÓN, Diario de a bordo. Mndrid: historia 16, 1985, pp. 106 e 166, respectivamente. Para os dados histónicos sobre o mito da llha de Cipango inseridos nesta nota, aproveitamos os que Luis Arranz proporciona na Introdução a esta edição do Diario colombiano (ver em particular as pp. 41-54).

(7) A tristeza, o sofrimento e a luta vā ínsitos no destino humano sâo, de fato, temas de implicação filośfica que impregnam todo o corpus poético de Augusto dos Anjos. No $E u$, por exemplo, existem dois momentos crnblemáti$\cos$ dessa visão augustiana do mundo que vale a pena frisar. No primeiro, pertencente ao soneto "Etema Mágoa" (como "A llha de Cipango", datado Pau d'Arco, 1904), assim se expressa o poeta sobre a imanência e irredutibilidade da tristeza e da mágoa na existência do homem: "O homem por sobre quem caiu a praga/ Da tristeza do Mundo, o homem que é triste / Para todos os séculos existe/E nunca mais o seu pesar se apaga!"; "Transpōe [a mágoa] a vida do seu corpo inerme;/E quando esse homem se transforma em verme / É essa mágoa que o acompanha ainda!" (A. dos ANJOS, Obra completa, op. cit., p. 290). No segundo poema, intitulado "Quejxas Notumas" (darado Pau d'Arco, 1906), Augusto dos Anjos se detém sobre o motivo da luta vã do homem, transfigurado na imagem de um Hércules que agoniza na derrota 
procedente das lutas travadas "contra a universal grandeza" $e$ "contra a Natureza"; condiçāo humana que o poeta considera inalterável: “Ah! Por todos os séculos vindouros / Ha de travar-se essa batalha vã / Do dia de hoje contra o de amanhã, / Igual à luta dos cristāos e mouros" (Ibidem, p. 292).

(8) C. D. Je ANDRADE, Obra completa, op. cit., p. 272.

(9) L. de CAMŌES, Os Lusíadas (ediçāo organizada por Emanuel Paulo Ramos). Porto: Porto Editora, 1990. pp. $337 \mathrm{e}$ 336 , respectivamente.

(1i) Ver, por exemplo, o que sobre a influência camoniana em Drummond refere Gilberto Mendonça Teles no breve comentário crítico feito ao texto de "A máquina do mundo", in: C. D. de ANDRADE, Seleta $\mathrm{em}$ prosa e verso. Rio: José Olympio/INL, 1971. p. 146.

(11) C. D. Je ANDRADE, Obra completa, op. cit., p. 272.

(13) Ibidem, p. 272-273. poral que marca o processo de aproximação e privação da condição edênicoutópica: Augusto dos Anjos é voltado mais para o passado, parte de uma condição esperançosa, ilusoriamente ditosa vivida no pretérito, para vê-la definitivamente perdida, no presente-futuro, por causas externas, alheias à sua vontade ("o vento que a Desgraça espalha"); em Drummond encontramos uma situação semelhante, embora temporalmente orientada mais para o presente-futuro: o poeta sempre almejou e se aplicou para obter algo que nunca conseguiu lograr (fase passada, de expectativa enganosa), e quando, no presente da narração, o objeto da sua procura se lhe depara diante dos olhos, é o próprio poeta a determinar o afastamento dessa felicidade presente-futura com a recusa da Máquina do Mundo, consoante aparece no final desta extraordinária sequiência imagética, verdadeira amplificatio do desalento humano:

"Mas, como eu relutasse em responder

a tal apelo assim maravilhoso,

pois a fé se abrandara, e mesmo o anseio,

a esperança mais mínima - esse anelo

de ver desvanecida a treva espessa

que entre os raios do sol inda se filtra;

como defuntas crenças convocadas

presto e fremente não se produzissem

a de novo tingir a neutra face

que vou pelos caminhos demonstrando, e como se outro ser, não mais aquele

habitante de mim há tantos anos,

passasse a comandar minha vontade

que, já de si volúvel, se cerrava

semelhante a essas flores reticentes

em si mesmas abertas e fechadas;

como se um dom tardio já não fora

apetecível, antes despiciendo,

baixei os olhos, incurioso, lasso,

desdenhando colher a coisa oferta

que se abria gratuita a meu engenho."12

É por essas características que o poema drummondiano, analogamente ao augustiano, pode ser lido como um poema da ilusão e desengano do homem diante do mundo, nisto mostrando submeter-se também a certa preocupação 
filosofante, pois o lirismo desalentado que caracteriza "A máquina do mundo" remonta, como se sabe, a uma fase poética drummondiana influenciada pelo existencialismo filosófico-literário do após-guerra. E é também nesta óptica existencialista que podemos interpretar a renúncia que o poeta viator faz do seu sonho de plenitude cognitiva, pois a escolha da renúncia é um modo de demonstrar a inevitabilidade do fracasso ontológico do ser humano, já que, na sua opiniāo,

\section{“[...] em vão e para sempre repetimos}

os mesmos sem roteiro tristes périplos,"13

Assim como em "A Ilha de Cipango" a intenção de Augusto dos Anjos transcender a sua condição subjetiva, inserindo-a numa continuidade histórica de experiências humanas fracassadas, testemunhava a natureza repetitiva e frustrada das ações humanas, igualmente, e dinamos mais explicitamente, a mesma intenção é revelada no poema drummondiano. Se essa condição, pois, é inerente à existência humana, então para os dois poetas é vã qualquer luta ulterior para melhorá-la: há, em ambos, a consciência de que a ruptura com o mundo, quer voluntária quer não, é inevitável, e ela, já detectada nos trechos poéticos transcritos, será, conforme veremos mais adiante, confirmada nos versos finais. Existem, pois, evidentes pontos de contato entre o pessimismo existencialista de "A máquina do mundo" e a tendência pessimista de "A llha de Cipango", que ajudam a reforçar ainda mais a aproximação analógica das duas composições poéticas.

\section{O FIM DO CAMINHO: DESCE A TREVA}

Após a longa cena do aparecimento das mirabilia, as últimas duas estrofes dos dois poemas são destinadas a retomar e desenvolver o motivo narrativo do exórdio: o poeta viator prossegue pela estrada, acompanhado, desta vez, pela vinda da treva, segundo uma continuidade das coordenadas espaço-temporais, que passando do exórdio para o epílogo, é capaz de proporcionar unidade estrutural e coesão diegética a ambos os poemas. A vinda do momento noturno pode dar-se ex abrupto e de forma sintética, como aparece em "A máquina do Mundo":

$$
\begin{aligned}
& \text { "A treva mais estrita já pousara } \\
& \text { sobre a estrada de Minas, pedregosa, } \\
& \text { e a máquina do mundo, repelida, }
\end{aligned}
$$

se foi miùdamente recompondo, enquanto eu, avaliando o que perdera, seguia vagaroso, de mãos pensas."14
(13) Jbidem, p. 271. 
(15) A. dos ANJOS, op. cit., p. $283-284$.
Ou, pelo contrário, de modo gradual, temporalmente escandido, e, por isso mesmo, com mais riqueza de pormenores, conforme vemos realizar-se em "A Ilha de Cipango":

"A tarde morre. Passa o seu enterro!...

A luz descreve ziguezagues tortos

Enviando à terra os derradeiros beijos.

Pela estrada feral dois realejos

Estão chorando meus amores mortos!

E a treva ocupa toda a estrada longa...

O Firmamento é uma caverna oblonga

Em cujo fundo a Via-Láctea existe.

E como agora a lua cheia brilha!

Ilha maldita vinte vezes a ilha

Que para todo o sempre me fez triste!"15

Contudo, as estrofes conclusivas têm outra importante função: confirmar a perda do sonho de felicidade, a ruptura definitiva do eu com o mundo - representado pelas duas mirabilia -, segundo idiossincrasias poéticas divergentes que, aliás, vimos caracterizar os poemas em vários de seus pontos. Com efeito, à repulsa da Máquina do Mundo, que o poeta viator Carlos Drummond de Andrade desempenha num tom pacato e numa aceitação desalentada que, por sua vez, se espelha na atitude cogitabunda e como que acidiosa do seu próprio semblante ("vagaroso" e "de mãos pensas"), faz de contraponto a atitude abertamente compungida do poeta viator Augusto dos Anjos, cuja desilusão é encarada com uma reação que desemboca no tom cáustico do anátema lançado contra a Ilha de Cipango, a "Ilha maldita", causa da sua perene tristeza. Características, estas, de dois poemas tão diferentes e contudo tão semelhantes, capazes de tramar um sugestivo diálogo, a distância de tempo e de espaço, sobre o sentido da vida e existência humanas: "A máquina do mundo n' "A Ilha de Cipango".

ABSTRACT: From the poet-viator's image this essay compares the analogies of the structure, the images and the mythical themes of two poems: Augusto dos Anjos's "A ilha de Cipango" and Carlos Drummond de Andrade's "A máquina do mundo"; as well as the similar attitude of both authors that reject the world by the negation of the Utopia. KEYWORDS: poetry; myth; utopia.

Ensaio elaborado no primeiro semestre de 1999, para o curso de Pósgraduação "Literatura e crítica literária na transição para o modernismo (18901922)", ministrado pelo Prof. Antonio Arnoni Prado. 